\title{
Uterine rupture- A 10 years review in tertiary hospital
}

\author{
S. Nagajyothi ${ }^{1, *}$, Sheela S.R ${ }^{2}$, Anudeep .P', Ranjith Meela ${ }^{4}$ \\ ${ }^{1}$ Resident, ${ }^{2}$ Professor, ${ }^{3,4}$ House Surgeons, Dept. of Obstetrics and Gynaecology, Sri Devaraj Urs Medical College and Research \\ Centre, SDUAHER, Kolar, Karnataka, India
}

*Corresponding Author:

Email: jyothireddy68@gmail.com

Received: $6^{\text {th }}$ April, 2016

Accepted: $13^{\text {th }}$ April, 2018

\begin{abstract}
Uterine rupture is a known potential catastrophic obstetric complication accounting for $9.3 \%$ of maternal deaths.

Aim: of this study is to evaluate the incidence, identify the risk factors as well as complications and to know the maternal and fetal outcome of rupture uterus.

Materials and Methods: The study was carried out in R.L. Jalappa medical college. All cases of uterine rupture admitted in hospital were analyzed from Jan 2006-Jan 2016 records. Included in the study.

Results: The incidence of uterine rupture was $0.6 \%$. Totally 108 cases of uterine rupture found in our study, majority of the women were in 26-30 years age group (48.1\%) and unbooked (79.6\%). The incidence was more in para 2 patients $37 \%$. The uterine rupture was most frequently seen in previous 2 LSCS $(36.2 \%)$ than previous one LSCS (26\%). The common cause of uterine rupture was previous LSCS (62\%), spontaneous rupture (18.5\%) and iatrogenic risk factors $(17.5 \%)$ The most common site of rupture was lower uterine segment in $98.1 \%$. We performed scar repair with sterilization (45.3\%) and without sterilization (45.3\%). Hysterectomy was performed in $23.14 \%$. Maternal complications noted in our study were anemia (98\%), puerperal sepsis $(12.9 \%)$, PPH $(55.6 \%)$, acute renal failure $(0.9 \%)$ and VVF $(0.9 \%)$. The perinatal mortality was $18.5 \%$.

Conclusion: Uterine rupture is a catastrophic condition. All the modern generation obstetricians should keep these rare complications in mind when they are dealing with postpartum morbidity patients. This is a preventable complication if women are provided with good antenatal care and intrapartum management.
\end{abstract}

Keywords: Hysterectomy, Lower segment caesarean section (LSCS), Postpartum hemorrhage (PPH), Uterine rupture, Scar repair.

\section{Introduction}

Uterine rupture is a potential catastrophic obstetric complication. It accounts for major fetal and maternal morbidity and mortality. In India, maternal mortality due to uterine rupture is around $5-10 \% .^{1}$ The incidence of this major obstetric hazard is increasing due to increase in incidence of cesarean section deliveries. The inadvertent use of uterotonics by unqualified people remains the major cause of rupture uterus. Many studies suggest close monitoring of trial of labor in women with previous cesarean section would be safer in an institution.But in India due to ignorance, illiteracy and poverty, the women do not take regular antenatal checkups. Several risk factors like deliveries conducted by unqualified people or traditional birth attendant, illiteracy, poor socioeconomic status, misuse of oxytocin, contracted pelvis, congenital uterine anomalies, multiparty, previous uterine surgeries like myomectomy, number and type of previous cesarean deliveries, instrumental deliveries, prolonged labor. However, there is a different scenario in developing countries due to increasing incidence of uterine rupture. Therefore, we tried to analyze the various risk factors, complications of maternal and fetal outcome in our institution.

\section{Objectives of the Study}

1. To evaluate the incidence of uterine rupture.

2. To identify the risk factors, complications of uterine rupture.

3. To know the maternal and fetal outcome in uterine rupture.

\section{Materials and Methods}

The study was carried out in R.L. Jalappa medical college and research centre. The data was analyzed Jan 2006-Jan 2016. All cases of uterine rupture admitted in hospital were included in the study.

Methodology: Patients admitted in the labor ward were assessed clinically. Socio demographic details, gestational period, previous obstetric history, duration of labor were recorded. The site of rupture, surgical treatment strategies, maternal and fetal outcome were analyzed. The surgical procedure was decided by taking following considerations: general condition of the patient, parity and desire for future child bearing, site, severity, extent of rupture. The patients were followed up until their discharge from hospital.

\section{Results}

Demographic variables $n=108$ 
Table 1: Age wise distribution

\begin{tabular}{|l|c|c|c|}
\hline S. No. & Demographic values & No of cases & Percentage \\
\hline 1. & Age & & \\
\hline & $20-25$ & 33 & 30.6 \\
& $26-30$ & 52 & 48.1 \\
& $31-35$ & 18 & 16.7 \\
& 36 and above & 05 & 4.6 \\
\hline 2. & Socioecnomic Status & & \\
\hline & Low & 78 & 72.2 \\
& Middle & 30 & 27.8 \\
\hline
\end{tabular}

Table 1 shows majority of the women were in 2630 years age group $(48.1 \%)$. An Indian study Sahu Lathika ${ }^{2}$ recorded this $73.12 \%$ of women belong to the age group of 20-30 years. K. Sunitha et $\mathrm{al}^{3}$ showed majority of the cases were in 26-30 years age group.

Table 2: Booking status or antenatal care

\begin{tabular}{|l|c|c|}
\hline Booking status & No of cases & Percentage \\
\hline Booked Cases & 22 & 20.4 \\
Unbooked Cases & 86 & 79.6 \\
\hline
\end{tabular}

Table 2 shows majority of the cases are unbooked (79.6\%) with us as shown in the above.

Table 3: Parity wise distribution

\begin{tabular}{|l|c|c|}
\hline \multicolumn{1}{|c|}{ Parity } & No. of cases & Percentage \\
\hline Para 0 & 03 & 2.8 \\
Para 1 & 36 & 33.4 \\
Para 2 & 40 & 37 \\
Para 3 & 29 & 26.8 \\
\hline
\end{tabular}

Table 3 shows the highest incidence was seen in multipara. The incidence was more in para 2 patients $37 \%$ when compared to other studies. Where in primipara was effected in a study conducted by Sunitha. $\mathrm{K}$ et $\mathrm{al}^{2}-52 \%$. Priyangi Purohit et $\mathrm{al}^{4}$ showed $63.3 \%$ of uterine rupture in multipara.

Table 4: Risk factors

\begin{tabular}{|l|c|c|}
\hline \multicolumn{1}{|c|}{ Risk Factors } & $\begin{array}{c}\text { No of } \\
\text { cases }\end{array}$ & Percentage \\
\hline Scar Rupture & & \\
\hline Previous one LSCS & 28 & 26 \\
Previous two LSCS & 39 & 36.2 \\
Previous uterine & 02 & 1.8 \\
surgeries & & \\
\hline Spontaneous Rupture & & \\
\hline Cephalopelvic & 11 & 10.1 \\
disproportion & 05 & 4.6 \\
Multiparity & 04 & 3.7 \\
Malpresentation & & \\
\hline Iatrogenic Rupture & 04 & 3.7 \\
\hline Instrumental delivery & 06 & 5.6 \\
Induction of labor & 02 & 1.8 \\
Use of PGE 2 & 07 & 6.4 \\
Oxytocin
\end{tabular}

Table 4 shows the uterine rupture was most frequently seen in previous 2 LSCS (36.2\%) than previous one LSCS (26\%). The causes for spontaneous rupture in our study is CPD (10.1\%), multiparity $(4.6 \%)$, malpresentation $(3.7 \%)$. Iatrogenic risk factors were 4 cases following instrumental delivery (vacuum), 8 cases due to induction of labor.

Out of 7 cases of oxytocin induction, 6 cases were induced in other hospital and referred to us.

Table 5: Type of uterine rupture $(n=108)$

\begin{tabular}{|l|c|c|}
\hline \multicolumn{1}{|c|}{$\begin{array}{c}\text { Type of uterine } \\
\text { rupture }\end{array}$} & $\begin{array}{c}\text { No of } \\
\text { cases }\end{array}$ & Percentage \\
\hline Complete rupture & 48 & 44.5 \\
Incomplete rupture & 35 & 32.4 \\
Scar dehiscence & 25 & 23.1 \\
Lower segment & 106 & 98.1 \\
rupture & 02 & 1.8 \\
Upper segment & & \\
rupture & 05 & 4.6 \\
Broad ligament & & \\
hematoma & 02 & 1.8 \\
Colporrhexis & \\
\hline
\end{tabular}

Table 5 gives intraoperative findings of site and type of rupture. Complete rupture seen in $44.5 \%$ of cases. Incomplete rupture cases (32.4\%) diagnosed by uterine tenderness, vaginal bleeding and non-reassuring fetal heart rate patterns. Scar dehiscence in $23.1 \%$ cases. The most common site of rupture was lower uterine segment in 106 cases. Upper uterine segment is very less accounting for $1.8 \%$ of the cases. The other associated conditions were broad ligament hematoma noted in 5 cases and Colporrhexis in 2 cases.

The site of lower uterine segment rupture was comparable with Sahu Lathika ${ }^{1}$ study ( $88.72 \%$ cases).

Table 6: Surgical management

\begin{tabular}{|l|c|c|}
\hline \multicolumn{1}{|c|}{ Management } & $\begin{array}{c}\text { No of } \\
\text { cases }\end{array}$ & Percentage \\
\hline Scar repair & 83 & 76.8 \\
\hline With sterilization & 49 & 45.3 \\
\hline Without sterilization & 34 & 31.5 \\
\hline Hysterectomy & 25 & 23.14 \\
\hline Associated Surgeries & 40 & 37 \\
\hline Bladder repair & 05 & 4.6 \\
\hline
\end{tabular}




\begin{tabular}{|l|c|c|}
\hline Colporrhexis repair & 03 & 2.8 \\
\hline $\begin{array}{l}\text { Internal iliac artery } \\
\text { ligation for PPH }\end{array}$ & 32 & 29.6 \\
\hline Blood Transfusion & 107 & 99 \\
\hline
\end{tabular}

Table 6 shows our study showed $76.8 \%$ of the cases, we performed scar repair with sterilization $(45.3 \%)$ and without sterilization (45.3\%). Hysterectomy was performed in 25 cases of uterine rupture. Associated surgeries like internal iliac artery ligation in 32 cases, bladder repair in 5 cases and Colporrhexis repair in 3 cases. Majority of the patients nearly $99 \%$ required blood transfusion.

Table 7: Maternal outcome

\begin{tabular}{|l|c|c|}
\hline $\begin{array}{c}\text { Maternal } \\
\text { complication }\end{array}$ & $\begin{array}{c}\text { No of } \\
\text { cases }\end{array}$ & Percentage \\
\hline Anemia & 106 & 98.1 \\
\hline Puerperal sepsis & 14 & 12.9 \\
\hline Postpartum hemorrhage & 60 & 55.6 \\
\hline Acute renal failure & 01 & 0.92 \\
\hline Vesicovaginal fistula & 01 & 0.92 \\
\hline
\end{tabular}

Table 7 shows maternal complication out of 108 , 106 anemia cases were corrected with blood transfusion. $12.9 \%$ of the cases were found to have puerperal sepsis. 55.6\% had PPH, Acute renal failure and VVF in 1 case.

Table 8: Perinatal outcome

\begin{tabular}{|l|c|c|}
\hline Perinatal outcome & No of cases & Percentage \\
\hline Still births & 15 & 13.9 \\
Live births & 93 & 86.1 \\
APGAR $<5$ at $1 \mathrm{~min}$ & 80 & 74 \\
APGAR $<5$ at $5 \mathrm{~min}$ & 37 & 34.2 \\
\hline Perinatal Mortality & 20 & 18.5 \\
\hline
\end{tabular}

Table 8 showed perinatal mortality in 20 cases, 93 live births, 15 cases of still birth.

\section{Discussion}

Uterine rupture is a most catastrophic condition (complication) in obstetrics. $0.6 \%$.

The incidence of uterine rupture in our centre is

As our hospital is a tertiary centre covering most of the rural population in and around kolar. Illiteracy, low socioeconomic status, negligence, home deliveries by traditional birth attendant (quacks) and delay in referrals are some of the factors contributing to uterine rupture.

Previous cesarean is the potential risk cause for uterine rupture. In our study previous cesarean accounted for $62 \%$ of uterine rupture cases. 4 cases of uterine rupture in this study, there was history of previous classical cesarean section. In 2 cases the previous surgeries were curettage (1.8\%).
This implicates previous surgical management or interference had a devastating effect in the subsequent pregnancies.

1. In our study we have also found the other major direct factors for uterine rupture

i. Obstructed labor

ii. Instrumental delivery

iii. Induction, Augmentation of labor

2. Obstructed labor, spontaneous cause of uterine rupture. In our study, this was mainly due to Cephalopelvic disproportion (10.1\%), malpresentation (3.7\%).

3. $93 \%$ of uterine rupture due to obstructed labor was reported in Ethiopia.

4. In modern obstetrics, vacuum assisted deliveries is being increasingly used. However the obstetrician should always keep in mind about pros and cons of using a vacuum. Of course the use of it has reduced the rate of cesarean section but the most rare but possible complication of instrumental delivery like uterine rupture should be suspected whenever there is intractable bleeding.

5. In our study we have recorded in 4 cases $(3.7 \%)$ following vacuum extraction.

6. Induction of labor with prostaglandins and augmentation of labor are other obstetric iatrogenic factors leading to uterine rupture. Our study showed $7.4 \%$ of uterine rupture with induction of prostaglandins. Augmentation of labor with oxytocin for active management of labor was used for already prolonged and obstructed labor instead of taking measure for active management of labor. Trial of labor in previously scarred uterus can be safe if the protocols are well accomplished. Injudicious use of oxytocin before referral to hospital has lead to uterine rupture of $6.4 \%$ in our observational study.

In our study the uterine ruptures were complete $44.5 \%$, incomplete $32.3 \%$ and lower segment uterine rupture $(16.7 \%)$ was seen.

In a study Co Fofie et $\mathrm{al}^{5}$ reported $80.5 \%$ were complete and $19.5 \%$ were incomplete. Other study by K. Sunitha et $\mathrm{al}^{3}$ showed complete $88 \%$ and $6 \%$ were complete and incomplete.

The surgical management in our centre was planned by experienced obstetricians.

Out of 108 patients in only $23.14 \%$ of the cases hysterectomy was done. 
Table 9: Comparison of surgical intervention with other studies

\begin{tabular}{|l|c|c|c|c|c|}
\hline S. No & Intervention & Present Study & $\begin{array}{c}\text { K. Sunitha } \\
\text { et al }\end{array}$ & $\begin{array}{c}\text { Rashmi }^{\mathbf{6}} \\
\text { et al }\end{array}$ & $\begin{array}{c}\text { AE DIAB }^{\mathbf{7}} \\
\text { et al }\end{array}$ \\
\hline 1. & $\begin{array}{c}\text { Uterine rupture with or } \\
\text { without sterilization }\end{array}$ & $76.8 \%$ & $68 \%$ & $54 \%$ & $48 \%$ \\
\hline 2. & Subtotal hysterectomy & $23.14 \%$ & $32 \%$ & $46 \%$ & $55 \%$ \\
\hline
\end{tabular}

Table 9 shows intervention in our study are uterine rupture with or without sterilization (77\%) and subtotal hysterectomy (23.14\%) compared to other studies.

Other associated surgeries like bladder repair in 5 cases and internal iliac artery ligation in 32 cases were done.

In other studies Sahu Lathika study ${ }^{2}$ showed out of 252 women with uterine rupture, 105 cases underwent hysterectomy.

Major maternal complication like anemia in 106 cases and post partum hemorrhage in 60 cases. The other complications are puerperal sepsis in 14 cases which was combated by higher antibiotics.

Acute renal failure and VVF were very less in the study.

Literature from Yemen study reported VVF incidence of $3.5 \%{ }^{7}$

There was one case of mortality due to intraoperative bleeding and DIC.

The perinatal outcome was also observed in our study. The perinatal mortality was $18.5 \%$ compared to other studies. Sahu Latike ${ }^{2}$ showed $94.07 \%$. Ishraq Dhaifalah et $\mathrm{al}^{8}$ reported $54.3 \%$ of perinatal mortality.

\section{Conclusion}

Uterine rupture is a known potential catastrophic obstetric complication. These cases should be properly assessed and aggressive management to save both mother and the baby. All the modern modern generation obstetricians should keep these rare complications in mind when they are dealing with postpartum morbidity patients. This is a preventable complication with good antenatal care and intrapartum management. In our study, we have recognized this condition in time and appropriate surgical interventions were made like 1) Scar repair 2) Hysterectomy 3) Internal iliac artery ligation. And we advocated initial conservative management to stabilize the patient with blood and blood products transfusion etc. We recommend hysterectomy together with internal iliac artery ligation is a good surgical option in multiparous women.

\section{References}

1. Bhaskar Rao K, Obstructed Labor. In Ratnam SS, Bhasker Rao K, Arulkumaran S (eds). Obstetrics and Gynecology for Postgraduates Vol 1. 1st edn. Madras, Orient Longman. 1992;130-2.

2. Sahu Latika. A 10 year analysis of uterine rupture at a teaching institution. J Obstet Gynecol India. 2006;56(6):502-506.
3. K Sunitha, I Indira, P Suguna. Clinical Study of Rupture Uterus - Assessment of Maternal and Fetal Outcome. IOSR Journal of Dental and Medical Sciences (IOSRJDMS). 2015; 14;39-45.

4. Priyangi Purohit, Latika R Mehta, Yogesh R. Rathava, Nilesh Chauhan. "Rupture Uterus-An Obstetric Emergency": Study of 30 Cases. 2013;2:11. ISSN No 2277-8160.

5. CO Fofie and P Baffoe. A Two-Year Review of Uterine Rupture in a Regional Hospital. Ghana Med J. 2010;44(3):98-102.

6. Rashmi, G Radhakrisknan, N.B. Vaid, N. Agarwal. Rupture uterus--changing Indian scenario. J Indian Med Assoc. 2001;99(11):634-637.

7. AE Diab. Uterine rupture in Yemen. Saudi Medical Journal. 2005;26(2):264-269.

8. I. Dhaifalah, J. Santavy, H. Fingerova. Uterine rupture during pregnancy and delivery among women attending the AL-tthawra hospital in Sana'a city Yemen Republic. Biomed Pap Med Fac Univ Palacky Olomouc Czech Repub. 2006;150(2):279-283.

How to cite this article: Nagayothi S, Sheela S.R, Anudeep .P, Meela R. Uterine rupture- A 10 years review in tertiary hospital. Ind J Obstet Gynecol Res. 2018;5(3):409-412. 